\title{
Psicologia, Loucura e Justiça: os Laudos Psicológicos Produzidos no IPF
}

\author{
Eduardo Coser Eggres ${ }^{1,2}$ \\ ${ }^{1}$ Centro Universitário Cenecista, Bento Gonçalves, RS, Brasil. \\ ${ }^{2}$ Centro Universitário Uniftec, Bento Gonçalves, RS, Brasil.
}

\author{
Rosane Azevedo Neves da Silva ${ }^{3}$ \\ ${ }^{3}$ Universidade Federal do Rio Grande do Sul, \\ Porto Alegre, RS, Brasil.
}

Resumo: Este artigo busca compreender, desde uma perspectiva arqueogenealógica, a produção de laudos psicológicos no contexto do Instituto Psiquiátrico Forense Maurício Cardoso (IPF) entre 1989 e 2016. Para tal, realiza-se um breve percorrido histórico da reforma do sistema penal do final do século XVIII, com o estabelecimento de uma nova racionalidade penal e dos tensionamentos que o crime sem razão produz neste regime de verdade. Com isso, pretende-se situar a produção dos laudos psicológicos no campo de relações entre os discursos jurídico e psiquiátrico. Foram analisadas 263 papeletas administrativas catalogadas no arquivo do IPF, o que resultou na seleção de 43 documentos produzidos por psicólogos para compor o escopo da pesquisa. Os laudos foram divididos em cinco períodos, nos quais podem ser identificados três regimes discursivos: um regime explicativo, fundado nas relações entre desenvolvimento, instinto e perigo; um regime marcadamente disciplinar, de vigilância e relato; e, por fim, um regime discursivo, que funciona por meio de uma modulação do poder de cuidado.

Palavras-chave: Manicômio Judiciário, Arqueogenealogia, Laudo Psicológico.

\section{Psychology, Madness, and Justice: the Psychological Reports Produced by the Forensic Psychiatric Institute Maurício Cardoso}

\begin{abstract}
This article aims to understand the production of psychological reports in the Forensic Psychiatric Institute (FPI) Maurício Cardoso between 1989 and 2016 from an archaeogenealogical perspective. To locate the production of psychological reports in the field of relations between judicial and psychiatric discourses, this study performed a brief historical review of the 18th-century penal system reform, which established a new criminal rationality and heightened the tensions produced by crimes without reason in this regime of truth. From the 263 administrative folders cataloged in the FPI archive, 43 documents written by psychologists were selected for the research scope. These documents were analyzed and divided into five different moments, indicating three discursive regimes: an explanatory one, founded on the relations between development, instinct, and danger; a disciplinary regime of surveillance and reporting; and a discursive regime that works through the modulation of care power.
\end{abstract}

Keywords: Judicial Asylum, Archeogenealogy, Psychological Report.

\section{Psicología, Locura y Justicia: los Informes Psicológicos Producidos por el Instituto Psiquiátrico Forense Maurício Cardoso}

Resumen: Este artículo pretende comprender, desde la perspectiva arqueogenealógica, la producción de informes psicológicos por el Instituto Psiquiátrico Forense Maurício Cardoso 
(IPF) en el período entre 1989 y 2016. Para ello, se realiza un breve recorrido histórico de la reforma del sistema penal de finales del siglo XVIII, con el establecimiento de una nueva racionalidad penal y de las tensiones que el delito sin razón produce en este régimen de verdad. Lo que se propone es situar la producción de los informes psicológicos en el campo de relaciones entre los discursos jurídico y psiquiátrico. Se analizaron 263 papeletas administrativas catalogadas en el IPF, lo que resultó en la selección de 43 documentos producidos por psicólogos para componer el corpus de la investigación. Los informes se dividieron en cinco períodos en que pueden ser identificados tres regímenes discursivos: el explicativo fundado en las relaciones entre desarrollo, instinto y peligro; el marcadamente disciplinario, de vigilancia y relato; y, por fin, el discursivo que funciona mediante una modulación del poder de cuidado.

Palabras clave: Manicomio Judicial, Arqueogenealogía, Informe Psicológico.

\section{Introdução}

No Brasil, desde a aprovação da Lei no 10.216/01 conhecida como Lei da Reforma Psiquiátrica -, busca-se a superação do modelo asilar no campo da saúde mental. Não sem resistências e disputas, a criação de serviços substitutivos e a garantia de direitos no campo legal têm mobilizado uma série de discussões acerca do tema nos últimos anos.

Apesar dos importantes avanços conquistados nas últimas décadas, Diniz (2013) afirma que os Hospitais de Custódia e Tratamento Psiquiátrico (HCTP) resistiram à Lei da Reforma Psiquiátrica: "de 2000 a 2010, foi construído $1 / 4$ dos manicômios judiciários brasileiros" (Diniz, \& Brito, 2016, p. 114). Os primeiros manicômios judiciários brasileiros, no entanto, datam da década de 1920 e são fruto de uma psiquiatria que passa a se institucionalizar como um campo da medicina social, ocupando-se do controle e vigilância de uma população dita desviante.

As marcas da exclusão e invisibilidade que recaem sobre a população internada em tais instituições são reforçadas pelo fato de que, apesar de tratarmos de instituições com quase 100 anos de existência, o primeiro estudo censitário (Diniz, 2013) realizado com esta população data do ano de 2011. Segundo Diniz (2013), em 2011, o Brasil contava com 23 Hospitais de Custódia e Tratamento Psiquiátrico e três Alas de Tratamento Psiquiátrico localizadas em complexos penitenciários.

De 2011 para cá, podemos constatar a criação de um hospital de custódia no estado do Amapá no ano de 2017 e a existência de um projeto de lei, de 2011, para a criação de um outro hospital de custódia, no estado do Tocantins. Tal cenário confirma a expansão destas instituições no país, contrariando o que fora proposto pela Lei da Reforma Psiquiátrica.
A medida de segurança se configura como o dispositivo legal que regula as internações em manicômios judiciários no Brasil, ela "representa a intervenção estatal na liberdade do indivíduo inimputável em razão de doença mental, que cometeu fato típico e antijurídico" (Prado \& Schindler, 2017, p. 629). Nesse sentido, a medida de segurança tem dupla função: a de tratamento do indivíduo, visando a cessação de sua periculosidade, e a de defesa da sociedade do risco representado por tais indivíduos.

Este modelo de ação penal, estabelecido por meio da medida de segurança, se institucionaliza como dispositivo psiquiátrico-penal no Brasil apenas a partir do Código Penal de 1940. No entanto, as discussões a respeito da injunção crime-loucura, imputabilidade, responsabilidade moral e defesa social acompanharam a produção dos códigos penais brasileiros desde o Código Criminal do Império, de 1830, passando pelo Código Penal de 1890 até o Código de 1940.

Com a institucionalização da medida de segurança, temos também a formalização do manicômio judiciário como destino privilegiado ao louco infrator. Segundo Peres e Nery Filho (2002, p. 345), o dispositivo da medida de segurança surge "para possibilitar ao direito penal um espaço de atuação frente aos irresponsáveis".

A legislação atual, por meio da reforma do Código Penal de 1984, define no art. 26 que se isenta de pena: "o agente que, por doença mental ou desenvolvimento mental incompleto ou retardado, era, ao tempo da ação ou da omissão, inteiramente incapaz de entender o caráter ilícito do fato ou de determinar-se de acordo com esse entendimento" (Lei no $7.209,1984$ ).

Assim, o art. 97 estabelece que, sendo o agente inimputável, o juiz determinará sua internação. No parágrafo primeiro, define que a internação durará 
tempo indeterminado, com prazo mínimo de um a três anos e perdurará "enquanto não for averiguada, mediante perícia médica, a cessação de periculosidade" (Lei no 7.209 , 1984).

Dessa forma, é no campo de imbricação jurídico-psiquiátrico que será produzido o dispositivo da medida de segurança, no qual ocorre um deslocamento do olhar jurídico do ato à conduta, assim, o alvo da ação psiquiátrico-penal é o próprio corpo do indivíduo a ser corrigido, tendo em vista que o fenômeno da periculosidade passa a ser situado no indivíduo.

No estado do Rio Grande do Sul, localiza-se o Instituto Psiquiátrico Forense Maurício Cardoso (IPF). Criado em 1925, esse é o segundo hospital de custódia mais antigo do Brasil, atrás apenas do Manicômio Judiciário do Rio de Janeiro, fundado em 1921. Vinculado à Superintendência de Serviços Penitenciários do Rio Grande do Sul (SUSEPE), o IPF recebe para internação sujeitos que cumprem medida de segurança, sendo "responsável também pela avaliação psiquiátrica pericial de todas as pessoas que cometeram delitos na vigência da suspeita de algum comprometimento mental" (Kummer, 2010, p. 7).

É neste contexto que surge a pesquisa "Psicologia, Loucura e Justiça: os Laudos Psicológicos produzidos no IPF", com o intuito de compreender o papel da psicologia quando chamada a subsidiar decisões judiciais a respeito dos internos do Manicômio Judiciário do Rio Grande do Sul. Dessa forma, a pesquisa debruça-se sobre um campo de relações de saber e poder que, formalizadas em um objeto de análise os documentos escritos produzidos por psicólogos no Instituto Psiquiátrico Forense Maurício Cardoso (IPF), estendem-se por uma vasta superfície de disputas, embates e lutas.

Disputas discursivas, embates conceituais e lutas políticas compõem o campo de uma análise que busca compreender a composição de dispositivos que organizam a implementação de uma política específica frente ao fenômeno crime-loucura. A partir disso, nos ocupamos da análise de uma série de técnicas que fazem funcionar a maquinaria do manicômio judiciário por meio do discurso psicológico.

\section{Metodologia}

Para percorrermos tais questões, foram analisados os documentos escritos produzidos por psicólogos no IPF que, direta ou indiretamente, compõem processos judiciais. Tal análise parte de uma inspiração arqueogenealógica, atenta aos determinantes históricos que compõem o campo de pesquisa.

Ao analisarmos a produção destes documentos, o que está em jogo não é a avaliação da correta aplicação de protocolos e prescrições técnicas, mas a imbricação de práticas e discursos que produzirão um tipo discursivo bastante específico e que passará a operar em mais uma rede de poder quando atrelada ao judiciário. Interessa-nos, dessa forma, identificar as modulações discursivas que se apresentarão ao longo do tempo e da história do IPF. Trata-se, portanto, de mapear os processos de "purificação" de um campo discursivo que irá traduzir-se na produção do laudo psicológico.

Dessa forma, a proposta metodológica aqui sustentada aponta uma articulação de ferramentas, tanto da arqueologia quanto da genealogia foucaultianas, para a proposição de uma arqueogenealogia. Esta articulação é tomada não no sentido de propor uma homogeneização destas duas abordagens metodológicas, mas de apontar seu caráter de complementaridade, possibilitando diferentes pontos de entrada para a problematização do campo de pesquisa.

Enquanto o arqueólogo descreve e analisa as práticas discursivas, o genealogista mostra sua relação com as práticas não discursivas, que sujeitam indivíduos, corpos, populações a mecanismos de poder, um deles, o menos suspeito e o mais generalizado e prestigiado, o jogo de verdade. . . O genealogista trabalha a partir das descrições e objetivações do arqueólogo do saber (Araújo, 2007, p. 22-23).

Partindo desta perspectiva, os procedimentos de pesquisa foram distribuídos em quatro etapas. A primeira foi realizada após a obtenção de autorização da Vara de Execução de Penas e Medidas Alternativas de Porto Alegre, seguida do contato e definição de uma agenda para o acesso ao arquivo da instituição, por intermédio do seu responsável técnico. A partir disso, foram realizadas a localização e identificação de documentos escritos produzidos por psicólogos arquivados junto às papeletas administrativas no arquivo do IPF. Nesta etapa, foram analisadas 263 papeletas administrativas, nas quais foram localizados 67 documentos; destes, 43 foram utilizados na presente pesquisa.

Durante a análise das papeletas administrativas, foram selecionados todos os documentos assinados por psicólogos que continham em seu título alguma 
referência à psicologia (psicodiagnóstico, avaliação psicológica, parecer psicológico, laudo psicológico, entre outros), ou ainda documentos que faziam referência à utilização de alguma técnica privativa do campo da psicologia.

Concluída a primeira etapa da pesquisa, procedeu-se à leitura na íntegra dos documentos selecionados. Nesta etapa, foram incluídos na pesquisa apenas documentos estritamente produzidos por psicólogos, ou seja, foram desconsiderados documentos nos quais o profissional da psicologia não assinava como relator. Não foram incluídos documentos produzidos e assinados por psiquiatras, assim como foram excluídos aqueles produzidos pela equipe técnica responsável em que não houvesse seção específica destinada ao campo da psicologia.

Dessa forma, os dados amostrais desta pesquisa contam com 43 documentos escritos produzidos por psicólogos distribuídos entre os anos de 1989 e 2016. A partir dessa amostra, buscamos compreender a prática de produção de documentos psicológicos, assim como a constituição de um regime discursivo de verdade, além de suas eventuais reorganizações.

\section{Racionalidade penal}

Inicialmente, é necessário compreender, sob uma perspectiva histórica, as condições de possibilidade para a produção de dispositivos jurídico-psiquiátricos dentro de uma razão de punir específica que passa a se institucionalizar a partir das reformas do sistema judiciário e, notadamente, da justiça penal ocorrida entre o final do século XVIII e início do século XIX.

A organização de um poder judiciário regular é correlata ao surgimento das grandes monarquias europeias, constituindo-se como uma instituição ligada ao poder soberano. O crime, neste contexto, é compreendido como um ataque direto ao soberano. Dessa forma, a punição ao crime é a expressão da força soberana contra quem o atacou. Esta força é expressa, por exemplo, nas técnicas de suplício e nas execuções públicas, nas quais o poder do absoluto é restabelecido ritualmente (Foucault, 2009).

O suplício opera como vingança pessoal do soberano contra quem o ataca, não existindo uma relação de medida entre crime e punição. A punição apresenta-se como o excesso que responde ao crime e a ele deve prevalecer, enquanto o terror do castigo faz presente o horror do crime, reluzindo a vingança do soberano, tendo, por fim, a função de coibir novos crimes. Não há qualquer questão sobre a natureza do crime: "não há mecânica do crime que seria da alçada de um saber; não há mais que uma estratégia do poder, que exibe sua força em torno e a propósito do crime" (Foucault, 2001, p. 72).

Foucault (2009) aponta uma série de eventos e transformações que compõem uma processualidade posta em marcha a partir do século XVIII envolvendo as práticas penais. Encontramos, ao longo de todo o século XVII, uma certa margem de ilegalidade tolerada, com a inobservância de certas leis fosse por impossibilidade de sua aplicação efetiva, fosse por compor um certo funcionamento político e econômico que se tornara condição de sobrevivência para as camadas mais pobres.

Trata-se de uma espécie de isenção regular, composta tanto pelos privilégios do clero, da nobreza e da burguesia quanto por uma margem de tolerância a algumas ilegalidades dos pobres: "da ilegalidade fiscal à ilegalidade aduaneira, ao contrabando, ao saque, à luta armada contra os agentes do fisco. . . ou ainda da vadiagem (severamente punida por termos de ordenações nunca aplicadas)” (Foucault, 2009, p. 80).

Não obstante, desde o final do século XVII, é possível notar a diminuição dos crimes violentos, acompanhada de uma prevalência dos crimes contra a propriedade, "parte de todo um mecanismo complexo, onde figuram o desenvolvimento da produção, o aumento das riquezas e uma valorização jurídica e moral das relações de propriedade" (Foucault, 2009, p. 75). Se a ilegalidade dos direitos fora eventualmente incentivada pela burguesia, a ilegalidade dos bens se tornava insuportável.

Dessa forma, a partir de uma redistribuição da economia das ilegalidades marcada pelo desenvolvimento do capitalismo, coloca-se a necessidade de novos dispositivos de poder e controle que se capilarizem por todo tecido social. Torna-se imperativo, desse modo, a necessidade de se desfazer de um mecanismo incerto, lacunoso e inevitavelmente tolerante. Instala-se a procura por uma técnica indubitável em sua aplicação, que opere por meio de constante vigilância, submetendo a ilegalidade popular a um controle ininterrupto.

Pode-se observar, dessa forma, que não se trata de um aclamado avanço das luzes e da razão sobre o campo do direito. O que encontramos é uma complexa reorganização da economia do poder, fundamental para compreender a mudança jurídico-penal aqui 
abordada e suas implicações. O excesso do castigo criticado pelos reformadores ao final do século XVIII e início do século XIX está relacionado não apenas à crueldade da punição, mas fundamentalmente à sua irregularidade, expressando a necessidade de: "colocar novos princípios para regularizar, afinar, universalizar a arte de castigar. Homogeneizar seu exercício" (Foucault, 2009, p. 86).

Os reformadores do direito penal, pioneiros da Escola Liberal Clássica, produzirão, segundo Baratta (2016, p. 41), um modelo de ciência penal integrada "no qual ciência jurídica e concepção geral do homem e da sociedade estão estreitamente ligados". Trata-se, agora, não mais de reparar a ofensa cometida contra o rei, mas de defender a sociedade.

A noção de defesa social se articula a partir de uma série de princípios - de legitimidade, do bem e do mal, de culpabilidade, de prevenção, entre outros que organizam a nova racionalidade penal. Assim, temos a produção de um regime que garante a legitimidade do Estado para reprimir a criminalidade, condenando comportamentos desviantes e reafirmando valores e normas sociais.

Neste regime, o crime representa um dano contra a sociedade, de modo que o criminoso se torna um elemento disfuncional para esta, opondo o desvio criminal como o mal e a sociedade como o bem (Baratta, 2016). Se o crime representa o rompimento do pacto social, este rompimento é compreendido como a expressão de uma atitude interior reprovável, pois contraria os valores e as normas sociais, caracterizando a culpabilidade do criminoso. Deste modo, a pena não deve ter somente função de retribuição, mas de prevenção, já que deve representar a justa e adequada contramotivação ao comportamento delituoso (Baratta, 2016).

Os esforços dos reformadores levam, portanto, à constituição de uma nova racionalidade penal. Se, antes, havia uma máquina pesada de punição, marcada pelo poder do soberano, vemos surgir uma arte de punir na qual:

Encontrar para um crime o castigo que convém é encontrar a desvantagem cuja ideia seja tal que torne definitivamente sem atração a ideia de um delito. É uma arte das energias que se combatem, a arte das imagens que se associam, fabricação de ligações estáveis que desafiem o tempo (Foucault, 2009, p. 100)
A partir da constituição desta tecnologia da representação, temos o estabelecimento de um jogo de intencionalidades a ser decifrado no crime cometido. Trata-se de localizar a razão do crime, sem a qual torna-se impossível o cálculo da pena. Motivação, intenção, forma de execução, objetos utilizados, premeditação, entre outros, passam a compor um conjunto de variáveis que dissecam o delito. Não há mais o simples jogo da culpa pelo pecado e o arrependimento público, mas a construção da razão, do interesse do crime. Deve-se estabelecer a razão do crime para definir a razão da pena e se combater o que o anima, ir direto à sua fonte: "atrás dos delitos de vadiagem, há a preguiça; é esta que se deve combater" (Foucault, 2009, p. 102).

Era impensável para os reformadores do século XVIII que a reclusão recobrisse a maior parte das sanções impostas pelo aparelho penal. Uma pena uniforme seria incapaz de dar conta da variedade dos crimes e respostas penais necessárias: "esse teatro punitivo, com que se sonhava no século XVIII, e que teria agido essencialmente sobre o espírito dos cidadãos, foi substituído pelo grande aparelho uniforme das prisões" (Foucault, 2009, p. 112).

A generalização do encarceramento como resposta penal homogênea só é possível por uma mudança na economia geral do poder na sociedade. Dos exércitos às escolas, passando pelos hospitais e fábricas, temos, no século XVIII, a capilarização de uma série de mecanismos disciplinares de ação sobre os indivíduos. Se, no século XVII, os traços que marcam o soldado ideal são por ele carregados física e naturalmente, no século seguinte, "o soldado tornou-se algo que se fabrica” (Foucault, 2009, p. 131) por uma variedade específica de exercícios que inserem o corpo a um controle de seus movimentos e gestos a fim de adequá-lo à norma.

As disciplinas espalham-se pelo tecido social do século XVIII como formas de dominação dos corpos por meio de tecnologias de normatização, revelando um investimento político no corpo que caracteriza uma nova microfísica das relações de poder. Organizada em torno de técnicas disciplinares de correção, a partir do final do século XVIII e início do século XIX, a pena de encarceramento nas prisões constitui a penalidade da detenção.

A institucionalização de uma penalidade da detenção e os dispositivos disciplinares que passam a operar no espaço penitenciário criam condições de 
possibilidade para a produção de um saber biográfico a respeito do delinquente, produzindo a aproximação do poder jurídico ao poder psiquiátrico e possibilitando a constituição do campo da criminologia:

... vemos os discursos penal e psiquiátrico confundirem suas fronteiras; e aí, em seu ponto de junção, forma-se aquela noção de indivíduo "perigoso" que permite estabelecer uma rede de causalidade na escala de uma biografia inteira e estabelecer um veredicto de punição-correção. . . Nesse novo saber importa qualificar "cientificamente" o ato enquanto delito e principalmente o indivíduo enquanto delinquente. Surge a possibilidade de uma criminologia. (Foucault, 2009, p. 239-241)

A penitenciária, em seu exercício do poder disciplinar, cria o delinquente como objeto de conhecimento. Ao receber o infrator que rompeu com a lei, o poder disciplinar inventa o delinquente, que não é caracterizado - ou ao menos não apenas - pelo seu ato, mas pela sua biografia. $O$ delinquente está "amarrado ao seu delito por um feixe de fios complexos (instintos, pulsões, tendências, temperamento)" (Foucault, 2009, p. 239).

\section{0 crime sem razão}

Se o reformado sistema penal do início do século XIX funciona por meio de um regime de verdade, que compreende o crime como ação racional e motivada, organizado em torno de uma tecnologia a do exame - e que busca "desvelar a verdade sobre o criminoso (desvelando a racionalidade subjacente ao seu ato)" (Almeida, 2009, p. 71, grifo no original), encontramos, já no início do século XIX, casos que tensionam os limites deste regime de verdade.

Não é o louco criminoso. enquanto problema jurídico, que produzirá o campo em que os limites entre a psiquiatria e a justiça se confundem; é precisamente por meio de crimes nos quais a atribuição da loucura, o estabelecimento de uma razão ou de um interesse no crime escoam das mãos dos médicos e juristas que a psiquiatria entrará a passos firmes nos tribunais.

São casos como o de Henriette Cornier, que, após tomar para seus cuidados a filha da vizinha de sua patroa, a leva para um quarto, onde a decapita utilizando um facão. Quando a vizinha vai buscar sua filha, Henriette avisa que a menina está morta. Ao entrarem no quarto onde o corpo estava,
Henriette enrola a cabeça da menina em um avental e a atira pela janela. Ao ser presa, perguntam-na por que havia feito o que fizera, Henriette responde que foi uma ideia, sem nada acrescentar a isso. O crime de Henriette Cornier mobiliza o aparelho médico e judiciário em torno de um problema completamente novo posto pela racionalidade penal estabelecida no início do século XIX: a ausência de interesse exclui duplamente a possibilidade de inteligibilidade do crime e de sua punibilidade.

Temos, a partir dos crimes sem interesse, a articulação de diversas noções que sustentam uma espécie de força irrepreensível, de desejo irresistível, de paixão violenta, algo que será denominado "instinto". A ideia de um instinto incontrolável era incompatível à noção de loucura do início do século XIX, fortemente ligada à presença do delírio (Foucault, 2001).

Observa-se, neste momento, a passagem do ato sem razão ao ato instintivo, noção que será desenvolvida no interior do discurso psiquiátrico, fazendo surgir uma série de novas proposições, como as de pulsão, propensão, automatismo, impulso, de tal forma que "a psiquiatria do século XIX vai poder trazer às paragens da doença e da medicina mental todos os distúrbios, todas as irregularidades, todos os grandes distúrbios e todas as pequenas irregularidades de conduta que não pertencem à loucura" (Foucault, 2001, p. 112).

$\mathrm{O}$ instinto permite a constituição de uma ideia completamente nova à psiquiatria do século XIX: a de uma loucura sem delírio. Estes casos, entre outros registrados na primeira metade do século XIX, recebem grande atenção de ilustres psiquiatras da época, marcando não só "a intervenção da psiquiatria no âmbito penal” (Foucault, 1978/2006, p. 3), mas também as condições de possibilidade de um novo problema para a psiquiatria, que é o problema do anormal e das condutas anormais.

Segundo Foucault (2001), é justamente a partir do elemento instintivo que se torna possível observar a generalização do poder psiquiátrico por meio da integração da psiquiatria a certos mecanismos de poder, destacadamente a partir de uma lei de 1838, na França: uma regulamentação administrativa, que institui os estabelecimentos para o tratamento de doentes mentais. Entre as definições da lei, encontra-se o estabelecimento da internação ex officio, que regula a internação em hospitais psiquiátricos a pedido da administração pública, além disso, ela determina que a internação ex officio deve ser feita em estabelecimento especializado, 
com a função de receber e curar doentes mentais (Foucault, 2001, p. 120).

A internação ex officio coloca a psiquiatria como uma técnica de higiene pública, já que a internação deve ser motivada por uma alienação tal que pudesse provocar desordem e afetar a segurança pública. Podemos observar, por conseguinte, um deslocamento do objeto da psiquiatria. Se, no alienismo, encontrávamos o problema de estabelecer o estado de razão ou desrazão, a presença da demência ou estado de inconsciência, de alijamento da própria consciência, com a lei de 1838, "é a questão do distúrbio, é a questão da desordem, é a questão do perigo que a decisão administrativa coloca ao psiquiatra" (Foucault, 2001, p. 121). À psiquiatria não é mais colocada a questão a respeito do que pensa o doente, mas sim a respeito de o que ele poder fazer e o potencial de perigo e desordem social de seu comportamento.

Neste contexto, Foucault (2001) destaca a produção do gênero discursivo que dará conta da imbricação do campo jurídico com o campo psiquiátrico, afirmando que esta produção discursiva tem, de uma só vez, as seguintes propriedades:

A primeira é poder determinar, direta ou indiretamente, uma decisão de justiça, que diz respeito, no fim das contas, à liberdade ou à detenção de um homem. No limite... à vida e à morte. Segunda propriedade: de onde lhes vem esse poder? Da instituição judiciária, talvez, mas eles o detêm também do fato de que funcionam na instituição judiciária como discursos de verdade, discursos de verdade porque discursos com estatuto científico, ou como discursos formulados, e formulados exclusivamente por pessoas qualificadas, no interior de uma instituição científica. Discursos que podem matar, discursos de verdade e discursos ... que fazem rir (Foucault, 2001. p. 7).

Esta formulação discursiva cumpre uma função específica, já que busca repetir a infração, em um movimento tautológico, para marcá-la como traço do indivíduo. Esta operação ganha sua formalização justamente por meio das técnicas de exame, local privilegiado de superposição das relações de poder e saber.

O exame permite passar do ato à conduta, do delito à maneira de ser e de fazer a maneira de ser se mostrar como não sendo outra coisa que o próprio delito, mas, de certo modo, no estado de generalidade na conduta de um indivíduo (Foucault, 2001, p. 20).

Por conseguinte, desloca-se também o nível de realidade da infração, que passa de infração a uma irregularidade, um desvio que pode ser fisiológico, psicológico, moral, entre outros.

O percurso histórico apresentado até aqui permite uma breve contextualização no sentido de situar a produção dos laudos psicológicos na interface entre os discursos jurídicos e médico-legais.

\section{Os laudos psicológicos produzidos no IPF}

A partir da análise do material selecionado para compor o escopo da pesquisa, foi possível distribuir a produção de documentos escritos produzidos por psicólogos, considerando os seguintes períodos:

\section{9-1992: uma prática difusa}

Correspondem a este período 6 dos 43 laudos analisados na pesquisa. Destaca-se que estes documentos se caracterizam por terem sido solicitados por médicos peritos. Destes documentos, esperava-se a resposta a uma demanda específica: auxílio no esclarecimento do diagnóstico, sondar o tipo de estrutura psíquica do examinando, complemento ao exame psiquiátrico-legal, determinação de QI, resposta à hipótese sobre possibilidade de retardo mental, entre outros.

Dessa forma, neste primeiro momento, o trabalho dos psicólogos no IPF se caracterizava como prática auxiliar ao campo psiquiátrico, que funcionava a partir da demanda de médicos peritos. Entre psicodiagnósticos e avaliações psicológicas, temos uma prática difusa, que opera de forma complementar às tradicionais perícias psiquiátricas realizadas no IPF desde o início do século XX. Esta prática incipiente estabelece o contato inicial do campo jurídico-penal com o discurso psicológico que habita o Manicômio Judiciário do Rio Grande do Sul, já que partes destas avaliações são transcritas nos laudos psiquiátrico-legais enviados aos juízes responsáveis.

Apesar de uma prática difusa, organizada por meio de contornos confusos, é possível localizar alguns traços que constituem a articulação de um regime de verdade psicológico frente ao louco infrator. Neste ponto, destacam-se diferentes vertentes da 
noção de fracasso do desenvolvimento, em especial o emocional, assim como uma insistente hipótese sobre o excessivo esforço empregado para a manutenção do controle geral dos comportamentos, impulsos e instintos. A isso, somam-se avaliações moralizantes e normalizantes de toda ordem.

Tal cenário pode ser observado por meio de passagens como as do psicodiagnóstico de Luís ${ }^{1}$, realizado em 1991: "o examinando apresenta importantes dificuldades emocionais. A estrutura da personalidade mostra um desenvolvimento imcompleto ${ }^{2}$. É imaturo, dependente, demonstrando através da sua conduta, a falta de condições para tratar adequadamente os problemas que enfrenta”. Ainda, com recortes do psicodiagnóstico de Paulo, produzido em 1989, indicando "excessivo esforço para manter controle geral adequado", demonstrando um "auto-controle precário", assim como "tenta manter controlada sua impulsividade através da coerência e organização do pensamento (que se mostram frágeis) como forma de adequar suas resoluções", levando à conclusão de que "o examinando evidenciou, no conjunto da avaliação, com prejuízos significativos no desenvolvimento. . . que o impedem de relacionar-se adequadamente com o meio social e no âmbito pessoal".

De maneira geral, nos documentos até aqui analisados, encontra-se uma leitura psicodinâmica que sustenta o fracasso do desenvolvimento como uma operação transversal. As falhas no desenvolvimento, com suas implicações específicas, ajudam a construir uma inteligibilidade a respeito do louco-criminoso. Essa inteligibilidade não é mais evocada frente ao crime sem razão, mas frente ao próprio indivíduo criminoso que apresenta traços de anormalidade, demonstrando a acabada operação que se dá desde o surgimento da criminologia, com o deslocamento da atenção judiciária do delito para o indivíduo.

A articulação das noções de desenvolvimento mais especificamente, de seu fracasso - e de instinto não é nova no discurso psiquiátrico. Ao longo do século XIX, os debates a respeito da nosografia da idiotia e o retardo em crianças passa fundamentalmente pela noção de desenvolvimento, que apresenta, como fenômeno positivo, precisamente o instinto, entendido como "aquilo que da infância que, dado desde o início, vai aparecer como não integrado, em estado selvagem" (Foucault, 2006, p. 266). Surge, neste contexto, a criança anormal, que não apresenta sintomas, mas a liberação anárquica e selvagem dos instintos. O instinto é, para a anormalidade, o que o sintoma seria para a doença.

Ao não constituir a vontade obediente esperada do adulto normal, encontramos um indivíduo remetido a uma posição infantilizada de incapacidade de lidar com frustrações, assim como encontramos alguém que não desenvolveu as barreiras de civilidade esperadas de um adulto desenvolvido: entregue ao reino dos instintos, temos um indivíduo de quem é exigido um esforço descomunal para manter a agressividade controlada. Resulta, desta combinação, uma série complexa de inaptidões e inadaptações sociais.

\section{3-1996: laudos psiquiátricos-legais supervisionados}

A partir de 1993, é possível localizar laudos psiquiátrico-legais produzidos e assinados por psicólogos. Esta prática estava submetida à supervisão de psiquiatras forenses e médicos supervisores periciais. Encontramos, assim, neste breve período de três anos, sete laudos com estruturação e nomeação notadamente psiquiátricas. Este movimento pode ser entendido como uma busca de legitimação institucional do campo da psicologia por meio da aproximação com uma prática historicamente reconhecida dentro dos muros do manicômio judiciário.

É notável que todos os documentos apresentados deste período são assinados por profissionais da psicologia como relatores e acompanhados de assinaturas de psiquiatras, psiquiatras forenses ou psiquiatras supervisores periciais. Se a psicologia, nos primeiros documentos localizados por esta pesquisa, cumpria função auxiliar em relação à psiquiatria, neste momento, localizamos uma prática subordinada à supervisão de psiquiatras, uma espécie de simulacro da prática de médicos peritos.

Destaca-se também a utilização de uma estrutura de documento similar aos documentos produzidos por psiquiatras no IPF, assim como a recorrente utilização de terminologia biomédica, presente em seções intituladas "Comentários Médico Legais", por exemplo. Ademais, temos a destituição de um caráter técnico explicativo presente nos psicodiagnósticos e avaliações psicológicas.

O que encontramos neste momento é um tipo discursivo descritivo e disciplinar, que buscará nas

\footnotetext{
${ }^{1}$ Para preservar a identidade dos pacientes, todos os nomes utilizados nas descrições dos documentos escritos produzidos por psicólogos são fictícios.

${ }^{2}$ Os documentos foram transcritos em seu formato original, não tendo sido realizadas correções gramaticais ou ortográficas.
} 
relações entre diagnóstico e vigilância institucional as condições determinantes de periculosidade. A conduta, apresentada pela experiência cotidiana do paciente no manicômio judiciário, é elevada ao nível de funcionamento geral do indivíduo, tanto em suas ações diárias quanto em suas expressões sintomatológicas: não participar de atividades lúdicas ou laborais e não corresponder a um padrão de deferência e docilização frente aos profissionais da instituição se tornam critérios que organizam o regime de verdade que se manifesta neste período.

É neste contexto que se encontra o laudo psiquiátrico-legal de Roberto, produzido em 1996. Registra-se a gradativa adaptação do paciente ao regime disciplinar da instituição: "passou a desenvolver atividades laborterápicas no setor de cozinha, conseguindo se integrar ao grupo e desempenhar as tarefas de forma adequada". Apesar disso, Roberto se mantém desconfiado e distante, sem estabelecer "relações de confiança com os outros, inclusive com sua terapeuta", de quem omitiu ter ameaçado, por carta, uma ex-namorada, "o que só recentemente admitiu".

Os comentários médico-legais do documento revelam que Roberto faz "crítica meramente racional de seu delito". A disciplina, o trabalho e o arrependimento organizam o discurso a respeito de Roberto e da ortopedia realizada pela instituição para operar a reforma do paciente.

Após 1996, não encontraremos outros documentos com as características dos que foram acima relatados, em especial no que diz respeito a uma aproximação com a estruturação de um documento psiquiátrico e a apropriação de termos médicos. Por meio do escopo desta pesquisa, não é possível precisar as condições específicas que organizam o surgimento desta prática, assim como sua interrupção. Apesar disso, é possível notar uma aproximação das práticas psicológicas ao campo pericial psiquiátrico do manicômio judiciário, já que passamos da produção de documentos para o auxílio de médicos peritos para a produção de documentos supervisionada por estes.

\section{6-2001: consolidação dos psicodiagnósticos e avaliações psicológicas - desenvolvimento- instinto-perigo}

A partir de 1996, voltamos a encontrar psicodiagnósticos produzidos por psicólogos no IPF. Passado o período entre 1993 e 1996, no qual a prática de produção de documentos escritos por psicólogos no IPF ganha contornos de produção médico psiquiátrica, temos a consolidação dos psicodiagnósticos até o final dos anos 1990 e início dos anos 2000. Tal movimento pode indicar uma maior autonomia e legitimação da prática psicológica dentro do manicômio judiciário se comparado a momentos anteriormente analisados. Correspondem a este momento cinco documentos.

Também a partir de 1996, observa-se um regime psicológico de verdade que opera por meio da tríade desenvolvimento-instinto-perigo, já presente nos primeiros documentos analisados na pesquisa. A figura do paciente, que tinha sua rotina institucional descrita a partir do dispositivo disciplinar de vigilância e relato, volta a ser a do examinando, que corresponde a uma figura a ser dissecada em termos psicológicos na produção de uma inteligibilidade capaz de estabelecer firmes relações de causalidade entre história pessoal, conduta, funcionamento e falhas psicológicas. Estabelece-se, assim, um jogo explicativo que desvela não as motivações do louco-criminoso, mas quem ele é, como age e por que.

Neste recorte, encontra-se o psicodiagnóstico de Jean. Os resultados obtidos apontam que o examinando apresenta "um potencial intelectual classificado como SUPERIOR registrando um percentil de 90 (máximo na escala do INV)". Seu raciocínio demonstra facilidade para abstrações, sua motricidade fina é adequada e, como nos psicodiagnósticos que encontramos no período entre 1989 e 1992, o problema de Jean está na área emocional.

Conclui-se que Jean é emocionalmente imaturo. Esta imaturidade é caracterizada pelas defesas que funcionam por meio da projeção e da onipotência. A intelectualização como defesa está ligada à sua facilidade para o raciocínio abstrato: "Estas defesas falham em situação de maior tensão, mostrando-se infantilizado e angustiado pelo desamparo". As frágeis defesas de Jean remetem a um estado infantil de um desenvolvimento que não se efetiva.

O retorno dos psicodiagnósticos mostra o retorno do regime de verdade psicológico organizado por meio da falha do desenvolvimento, quase sempre expressa pelos problemas na área emocional. No caso de Jean, a imaturidade, ou seja, processo incompleto de maturação de si, implica em dificuldades no reconhecimento do outro e no estabelecimento de uma relação de alteridade. Esta dificuldade no reconhecimento do outro é fator articulador de um discurso a respeito da periculosidade daquele que reconhece apenas a si, não vendo o outro como limitador de suas ações. 


\section{4-2009: consciência e conduta}

Circunscrito a este momento, são identificados seis documentos escritos produzidos por psicólogos. Estes documentos diferenciam-se das avaliações e psicodiagnósticos que buscam entender o funcionamento do indivíduo a partir da objetivação de suas falhas no desenvolvimento e identificação de seus impulsos e instintos incontroláveis. Diferenciam-se também do modelo médico psiquiátrico adotado no início da década de 1990, nos quais a psicologia opera um simulacro de discurso médico.

A conduta, anteriormente tomada como expressão de determinantes psicológicos, ganha neste espaço um novo campo. Neste período, encontramos uma espécie de modulação de um poder pastoral. Temos a organização de um regime discursivo orientado pela tarefa de conduzir o paciente a condições que possibilitem o fortalecimento de fatores de proteção que efetivem sua desinternação do manicômio judiciário.

Falamos da modulação de um poder pastoral na medida em que o que está em jogo é um poder de cuidado. O pastor é aquele que zela, "no sentido de vigilância do que pode ser feito de errado" (Foucault, 2008, p. 171), sendo esse um poder que opera como intermediário para o alcance de um objetivo. Evidentemente, não estamos num campo em que estaria em jogo a salvação, mas a boa condução do paciente, guiando-o para o fortalecimento de condições que garantam sua desinternação, tais como o apoio familiar e a vinculação a serviços substitutivos.

Não se trata de submeter os indivíduos a uma lei, mas de uma "sutil economia do mérito e do demérito" (Foucault, 2008, p. 228), estabelecendo os caminhos e prescrições para o paciente bem conduzir-se. Para tal, é necessária certa submissão aos parâmetros que condicionam a saída do manicômio judiciário sob o risco da reversão deste processo como punição a eventuais desvios.

Encontramos essa modulação do pastorado frente a um poder específico que tem por objeto a conduta dos homens, constituindo um sujeito "cujos méritos são identificados de maneira analítica, de um sujeito que é sujeitado em redes contínuas de obediência, de um sujeito que é subjetivado pela extração de verdade que lhe é imposta" (Foucault, 2008, p. 243). São traços que compõem uma estratégia que, de certa forma, transversaliza as práticas de avaliação e condução dos pacientes do IPF; contudo, esta modulação fica mais explícita à medida que exames de consciência e boa conduta ganham maior relevância sob o jogo de determinantes psicológicos que passam a definir os sujeitos.
Neste sentido, temos o parecer psicológico de Manuel, que participa de grupo terapêutico "com o objetivo de trabalharmos os fatores de risco e proteção com vistas a possível desinternação". Manuel mostrou-se "muito consciente de suas dificuldades", estabelecendo um comparativo com outros momentos "em que estando sob efeito de bebida, prejudicou-se". Por fim, indica-se a necessidade da manutenção da medida de segurança de internação de Manuel "por mais um período, tempo necessário para sedimentar sua vinculação ao tratamento na rede pública de saúde, tornando sua desinternação possível após esta vinculação".

É fundamental perceber que, mesmo colocada como uma premiação ao bem conduzir-se, a hipótese de desinternação passa a ser frequente nos documentos produzidos por psicólogos a partir da metade dos anos 2000. A recente aprovação da Lei da Reforma Psiquiátrica, assim como o fortalecimento da rede de serviços substitutivos, cumpre papel primordial neste contexto.

\section{0-2016: heterogeneidade}

Este período apresenta o maior volume de material coletado, correspondendo a 19 documentos. Se, até aqui, foi possível destacar regimes discursivos e práticas mais ou menos estáveis e convergentes, a partir de 2010 vamos encontrar uma descontinuidade nestes discursos e práticas. Estratégias pastorais de condução para condições necessárias à desinternação encontrarão uma interlocução com práticas psicologizantes, muitas vezes com uma base interpretativa que remete à localização de determinantes psicológicos que formam um fundamento explicativo a respeito dos indivíduos.

A partir da análise dos documentos, é possível indicar que, entre 2010 e 2016, há uma certa articulação das relações de poder e saber estabelecidas e consolidadas nos anos anteriores. Operam, ora dissociados, ora amarrados, regimes discursivos que dão conta tanto do indivíduo a partir de um prisma explicativo baseado em operações de extração da verdade psicológica quanto um regime descritivo das ações de condução do paciente às condições ideais para sua desinternação, referenciado pelo exame de consciência e a boa conduta.

Neste contexto, encontramos o parecer psicológico de Josué, apontando um histórico "de várias fugas e de momentos de agressão física a outros pacientes e de agressões verbais a funcionários deste hospital", além de descumprimento das regras do manicômio 
judiciário e consumo de bebida alcoólica. No último ano, entretanto, o paciente "vinha apresentando conduta adequada e bom juízo crítico".

Pela boa conduta, Josué "estava sendo preparado para ser beneficiado com a desinternação", porém, em uma de suas saídas em alta progressiva, o paciente apresenta "uma recaída, fez uso abusivo de bebida alcoólica retornando ao hospital alcoolizado". Josué fora conduzido à unidade fechada, "questionado pela equipe terapêutica o motivo que o fez realizar o uso da bebida alcoólica não conseguiu ter uma reflexão crítica sobre o fato ocorrido. Diz: 'mas foi só umas garrafinhas de catuaba com refrigerante' e 'eu bebi pouco, foi só um pouquinho'”.

Conclui-se que, devido a essa "nova situação será necessário que o paciente permaneça por mais um ano", período no qual será buscada uma nova articulação ao Centro de Atenção Psicossocial Álcool e outras Drogas (CAPS AD) e grupo de Alcoólicos Anônimos (AA) de sua região. O parecer psicológico de Josué articula de forma intensa pontos cruciais na organização dos regimes de verdade produzidos sob efeito de avaliações e documentos escritos por psicólogos no IPF.

Surge, paralelamente, um discurso disciplinar em torno do descumprimento de regras e a clássica questão do juízo crítico como determinante psicológico de seu comportamento, que assume um formato mais descritivo do que explicativo. Junto a isso, encontramos os temas em torno de um cuidado na condução do paciente às condições ideais para sua desinternação.

Não obstante, em meio a este processo, o paciente apresenta um desvio em sua conduta, o que reorganiza a articulação discursiva sob os mesmos pontos anteriormente apresentados. A falha disciplinar liga-se ao fracasso na reflexão crítica sobre o ocorrido, levando-nos a uma economia dos méritos e deméritos que tem como resultado a medida punitiva de pedido de manutenção da medida de segurança por mais um ano.

\section{Considerações finais}

A partir da leitura e análise dos laudos, foi possível localizar cinco momentos de organização e legitimação desta prática. O primeiro, de 1989 a 1992, coloca-nos frente a uma prática difusa, de contornos incertos, na qual é possível identificar a constituição de um regime de verdade em torno de problemas localizados na área emocional dos examinandos. Com base em uma articulação entre problemas no desenvolvimento, falta de controle dos instintos e perigo, as várias anormalidades dos loucos em conflito com a lei são tomadas desde um plano explicativo que produz uma inteligibilidade técnico-científica que faz operar o perigo por meio das anomalias do desenvolvimento.

Num segundo momento, entre 1993 e 1996, encontramos laudos psiquiátrico-legais produzidos e assinados por psicólogos, nos quais aparece um certo mimetismo entre a produção dos psicólogos e os tradicionais exames realizados pelo campo psiquiátrico pericial do IPF. O discurso psicológico passa a operar por meio da apropriação de uma terminologia biomédica, incorporando o modelo de documento psiquiátrico e sua nomenclatura. Surge, neste momento, um regime discursivo marcadamente disciplinar, que opera fundamentalmente por meio da vigilância e relato do cotidiano institucional dos pacientes.

Posteriormente, entre 1996 e 2001, temos o retorno dos modelos de avaliação psicológica e psicodiagnóstico, com sua consolidação como prática corrente e privilegiada entre psicólogos. Neste ponto, rearticula-se o dispositivo que opera por meio das relações entre desenvolvimento, instinto e perigo. Reorganiza-se, dessa maneira, o jogo explicativo que desvela o examinando, mostrando quem ele é, como age e por quais razões age.

Entre 2004 e 2009, encontramos, gradativamente, o encadeamento de um novo regime discursivo que incidirá sobre a conduta do paciente, composto por uma espécie de exame de consciência atrelado a referências que estabelecem o bom caminho pelo qual se deve conduzir o paciente à desinternação. Este tipo de modulação opera como um poder de cuidado, como intermediário para o alcance de um objetivo, buscando instaurar uma função reflexiva do bem conduzir-se.

Finalmente, entre 2010 e 2016, é possível apontar certa heterogeneidade e hibridismo entre as diferentes operações que até aqui organizavam o campo discursivo e a verdade psicológica no manicômio judiciário: a anormal falha no desenvolvimento como vetor explicativo, a vigilância e relato como dispositivo disciplinar e o bem conduzir-se como modulação de um poder de cuidado. Ora amarrados e operando no mesmo documento, ora funcionando isoladamente, estas três operações apresentam-se como agentes do discurso psicológico.

Buscamos, neste estudo, dar visibilidade à complexa trama de saberes e práticas que atravessa e constitui a produção de documentos psicológicos no contexto de um manicômio judiciário e que não é alheia aos múltiplos fatores envolvidos na problematização dos processos de desinstitucionalização que continuam a tensionar o fazer profissional da psicologia. 


\section{Referências}

Almeida, F. M. (2009). Fronteiras da Sanidade: "Periculosidade" e "risco" na articulação dos discursos psiquiátrico forense e jurídico no Instituto Psiquiátrico Forense Maurício Cardoso de 1925 a 2003 [Tese de Doutorado, Universidade Federal do Rio Grande do Sul].

Araújo, I. L. (2007). Formação discursiva como conceito chave para a arqueogenealogia de Foucault. Revista Aulas, 1(3), 1-24.

Baratta, A. (2016). Criminologia crítica e crítica do Direito Penal: Introdução à sociologia do Direito Penal. Editora Revan.

Diniz, D. (2013). A custódia e o tratamento psiquiátrico no Brasil. Editora UnB.

Diniz, D., \& Brito, L. (2016). "Eu não sou presa de juízo, não": Zefinha, a louca perigosa mais antiga do Brasil. História, Ciências, Saúde-Manguinhos, 23(1), 113-130.

Foucault, M. (2001). Os anormais: Curso no Collège de France (1974-1975). Martins Fontes.

Foucault, M. (1978/2006). A evolução da noção de "indivíduo perigoso" na Psiquiatria Legal do século XIX. In M. Foucault (Org.), Ética, sexualidade, política (pp. 1-25). Forense Universitária.

Foucault, M. (2006). O poder psiquiátrico: Curso no Collège de France (1973-1974). Martins Fontes.

Foucault, M. (2008). Segurança, território, população: Curso no Collège de France (1977-1978). Martins Fontes.

Foucault, M. (2009). Vigiar e punir: Nascimento da prisão. Vozes.

Kummer, L. O. (2010). A psiquiatria forense e o manicômio judiciário do Rio Grande do Sul: 1925-1941 [Tese de Doutorado, Universidade Federal do Rio Grande do Sul].

Lei $n^{\circ} 7.209$ (1984, 11 de julho). Altera dispositivos do Decreto-Lei no 2.848, de 7 de dezembro de 1940 - Código Penal, e dá outras providências. http://www.planalto.gov.br/ccivil_03/LEIS/1980-1988/L7209.htm

Peres, M. F. T., \& Nery Filho, A. (2002). A doença mental no direito penal brasileiro: inimputabilidade, irresponsabilidade, periculosidade e medida de segurança. História, Ciências, Saúde-Manguinhos, 9(2), 335-355.

Prado, A. M., \& Schindler, D. (2017). A medida de segurança na contramão da Lei de Reforma Psiquiátrica: Sobre a dificuldade de garantia do direito à liberdade a pacientes judiciários. Revista Direito GV, 13(2), 628-652.

\section{Eduardo Coser Eggres}

Mestre em Psicologia Social e Institucional pela Universidade Federal do Rio Grande do Sul (UFRGS), Porto Alegre RS. Brasil. Professor do Centro Universitário Cenecista (UNICNEC), Campus Bento Gonçalves - RS. Brasil. Professor do Centro Universitário Uniftec, Bento Gonçalves - RS. Brasil.

E-mail: eduardoeggres@gmail.com

(1) https://orcid.org/0000-0002-2222-6962

Rosane Azevedo Neves da Silva

Professora Titular do Instituto de Psicologia da Universidade Federal do Rio Grande do Sul (UFRGS), Porto Alegre - RS. Brasil.

E-mail: rosane.neves@ufrgs.br

(1) https://orcid.org/0000-0001-6486-0630

Endereço para envio de correspondência:

Rua Saldanha Marinho, 695, sala 503, Bairro Centro. CEP: 95700-080. Bento Gonçalves - RS. Brasil.

Recebido 18/03/2019

Aceito 08/10/2020

Received $03 / 18 / 2019$

Aceito 10//08/2020

Recibido 18/03/2019

Aceptado 08/10/2020 
Eggres, E. C., \& Silva, R. A. N. (2021). Psicologia, Loucura e Justiça.

Como citar: Eggres, E. C., \& Silva, R. A. N. (2021). Psicologia, loucura e justiça: os laudos psicológicos produzidos no IPF. Psicologia: Ciência e Profissão, 41, 1-13. https://doi.org/10.1590/1982-3703003221440

How to cite: Eggres, E. C., \& Silva, R. A. N. (2021). Psychology, Madness, and Justice: the Psychological Reports produced by the Forensic Psychiatric Institute Maurício Cardoso. Psicologia: Ciência e Profissão, 41, 1-13. https://doi.org/10.1590/1982-3703003221440

Cómo citar: Eggres, E. C., \& Silva, R. A. N. (2021). Psicología, Locura y Justicia: los Informes Psicológicos producidos por el Instituto Psiquiátrico Forense Maurício Cardoso. Psicologia: Ciência e Profissão, 41, 1-13. https://doi.org/10.1590/1982-3703003221440 